\title{
PENGEMBANGAN LKS FISIKA BERBASIS CONTEXTUAL TEACHING AND LEARNING MATERI SUHU DAN KALOR PADA SISWA KELAS XI SMA NEGERI 6 LUBUKLINGGAU
}

\author{
Inda Anggun Restu ${ }^{1}$, Wahyu Arini ${ }^{2}$ \\ indaanggunmeideran@gmail.com \\ ${ }^{1,2,3}$ Program Studi Pendidikan Fisika STKIP PGRI Lubuklinggau, Sumatera Selatan, Indonesia
}

Received: 6 Oktober 2020

Revised: 30 November 2020

Accepted: 10 Desember 2020

\begin{abstract}
This study aims to develop physics worksheets based on contextual teaching and learning materials for temperature and heat in class XI students of SMA Negeri 6 Lubuklinggau which aims to find out how to develop and quality valid, practical. The problem in this study is the valid and practical quality of the Physics Worksheet based on Contextual Teaching and Learning of Temperature and Heat. This research method is development (Research and Development) used is 4D (Four D) with 4 stages Define, Design, Develop and Desseminate. The population in this study was class XI IPA 2 with 28 students. The sampling technique used positive sampling using 6 samples. Data collection techniques in this study used interviews, diagnostic test questions, expert validation questionnaires, teacher response questionnaires, student response questionnaires and Physics Worksheets Based on Contextual Teaching and Learning. The results of the validation questionnaire data analysis with 3 validator experts were the results of the validation of the physics lecturer material 42, the results of the validation of the physics teacher material with a score of 46. The results of the validation of the linguists got a score of 18, the results of the validation of the media expert got a score of 34, so the final score obtained after validation of 35 with a very good category, the results of the 6 student response questionnaires obtained a score of 35.83 with the category of strongly agree and the results of the questionnaire response of the teacher and students got a score of 36.2 with the category of strongly agree. The results of competency test scores to support practicality obtained competency test scores obtained on average $76.5 \%$ complete reaching $\geq 73$. So it can be said that physics worksheets based on Contextual Teaching and Learning Material Temperature and Heat in Class XI Students of SMA Negeri 6 Lubuklinggau are valid. and practical. Keywords: Development, LKS, CTL, Valid, Practical
\end{abstract}

\begin{abstract}
Abstrak: Penelitian ini bertujuan mengembangan LKS fisika Berbasis Contextual Teaching and Learning Materi Suhu dan Kalor pada Siswa Kelas XI SMA Negeri 6 Lubuklinggau yang bertujuan mengetahui cara mengembangkan dan kualitas valid, praktis. Masalah dalam penelitian ini adalah kualitas valid dan praktis dari LKS Fisika Berbasis Contextual Teaching and Learning Materi Suhu dan Kalor. Metode penelitian ini adalah pengembangan (Research and Development) yang digunakan adalah 4D (Four D)dengan 4 tahapan Define, Design, Develop and Desseminate. Teknik pengambilan sampling menggunakan porposive sampling yang menggunakan 6 orang sampel. Teknik pengumpulan data dalam penelitian ini menggunakan wawacara, soal tes diagnosis, angket validasi ahli, angket respon guru, angket respon siswa dan LKS Fisika Berbasis Contextual Teaching and Learning. Hasil analisis data angket validasi dengan 3 ahli validator yaitu hasil validasi materi dosen fisika 42, hasil validasi materi guru fisika dengan skor 46. Hasil validasi ahli bahasa mendapatkan skor sebesar 18 , hasil validasi ahli media mendapatkan skor sebesar 34, sehingga skor akhir yang didapatkan setelah validasi sebesar 35 dengan katagori sangat baik, hasil angket respon 6 siswa diperoleh skor sebesar 35,83 dengan katagori sangat setuju dan hasil angket respon guru dan siswa mendapat skor sebesar 36.2 dengan katagori sangat setuju. hasil nilai uji kompetensi untuk menunjang kepraktisan memperoleh nilai uji kompetensi yang didapat rata-rata $76,5 \%$ tuntas mencapai $\geq 73$. Sehingga dapat dikatakan bahwa LKS fisika berbasis Contextual Teaching and Learning Materi Suhu dan Kalor pada Siswa Kelas XI SMA Negeri 6 Lubuklinggau telah valid dan praktis
\end{abstract}

Kata kunci: Pengmbangan, LKS, CTL, Valid, Praktis.

Puplished at https://ojs.stkippgri-lubuklinggau.ac.id/index.php/SJPIF 


\section{PENDAHULUAN}

Menurut Atma, (dalam mulyadi 2019) yang menyatakan bahwa kurikulum adalah program pendidikan yang disediakan oleh sekolah untuk siswa, melalui program yang direncanakan tersebut siswa melakukan berbagai kegiatan belajar sehingga mendorong perkembangan dan pertumbuhannya sesuai dengan tujuan pendidikan. Pendidikan merupakan aktivitas yang dilakukan antara dua orang atau lebih yang mempunyai tugas, sebagai pemberi dan penerima suatu ilmu yang digunakan untuk mencapai tujuan tertentu, melalui pendidikan kita mampu untuk berkontribusi dalam kemajuan kehidupan baik secara individu maupun secara berkelompok.

Menurut Salahudin, (2011) yang berpendapat bahwa pendidikan merupakan usaha yang dilakukan dengan sengaja dan sistematis untuk memotivasi, membina, membantu, dan membimbing seseorang untuk mengembangkan segala potensinya sehingga mencapai kualitas diri yang lebih baik. Sedangkan pendapat dari Syamsu (2019) menyatakan bahwa pendidikan adalah usaha sadar atau terencana secara aktif dapat mengembangkan potensinya supaya memiliki kekuatan kekuatan spiritual keagamaan, kepribadian, kecerdasan, serta keterampilan yang diperlukan dirinya dan masyarakat melalui proses sebuah pembelajaran. Pembelajaran fisika pada hakikatnya adalah sebuah cara untuk memperoleh kompetensi yang berupa keterampilan, memelihara sikap dan mengembangkan pemahaman konsep. yang berupa ilmu, fakta, konsep, prinsip hukum dan teori mengenai alam melalui pembelajaran fisika cara pandang berfikir siswa lebih sistematis dan terarah.

Pembelajaran fisika juga sebagai sarana edukatif dalam pembelajaran salah satunya dengan menerapkan model pembelajaran Contexual Teaching and Learning yang akan membuat pembelajaran lebih mudah untuk dipahami. Berdasarkan hasil observasi di SMA Negeri 6 Lubuklinggau, dimulai dari wawancara bersama guru dan siswa didapatkan sebuah informasi. Mengenai kriteria jumlah kriteria ketuntasan maksimal fisika di SMA Negeri 6 Lubuklinggau adalah 73, model pembelajaran yang digunakan dalam proses pembelajaran fisika di SMA Negeri 6 Lubuklinggau tersebut sudah masuk ke kurikulum 2013 namun untuk pelaksanaan pembelajaran masih menggunakan metode konvensial (ceramah). Pada proses pembelajaran tidak pernah melaksanakan pratikum, kendala jarang melaksanakan praktikum yang ditemukan adalah kurangnya fasilitas yang memadai, untuk penggunaan lembar kerja siswa pun tidak ada.

Peneliti melakukan tes diagnosis guna menambah informasi yang diperlukan bagi peneliti, yang dilaksakan menggunakan 9 siswa dengan tingkat 3 kemampuan yaitu, tinggi, 
sedang, dan rendah dan didapatlah hasil bahwa dari ke 9 siswa yang melakukan tes diagnosis tersebut hanya 2 siswa yang mendapat nilai 72 sedangkan untuk 7 siswa lain mendapat nilai 60 kebawah. Peneliti saat observasi kemarin juga mengamati tingkah laku siswa saat proses pembelajaran yang cenderung monoton, prilaku siswa terlihat merasa bosan dengan pembelajaran dan pasif. Bahan ajar yang mereka gunakan adalah buku paket yang dipinjam dari sekolah tersebut dan untuk penggunaanya pun mereka hanya menggunaan saat ada tugas saja, bentuknya seperti buku pelajaran pada biasanya namun, dalam sebuah pembelajaran yang jarang melakukan eksperimen mereka tidak menggunakan LKS. Setelah peneliti selesai observasi, didapatlah hasil yang didapatkan sebuah informasi bahwa tingkat pemahaman siswa terhadap sebuah pelajaran sangat dipengaruhi oleh motivasi, cara belajar, bahan pembelajaran, pengolahan kelas dan model yang digunakan yang mampu membuat siswa aktif, kreatif dan mandiri. Salah satu upaya untuk menyelesaikan masalah tersebut adalah seorang peneliti yang mengembangkan sebuah bahan ajar berupa LKS fisika yang berbasis Contextual Teaching and Learning materi suhu dan kalor di SMA Negeri 6 Lubuklinggau, secara ringkas dan menarik yang nantinya akan digunakan oleh peserta didik secara mandiri menemukan dan menyerap informasi, serta dapat menujang proses pembelajaran pada kurikulum 2013.

Alasan perlu diterapkan pembelajaran Contextual Teaching and Learning berdasarkan definisi Fisika merupakan ilmu yang mempelajari tentang gejala alam sehingga pembelajaran kontekstual sangat cocok sekali dalam mata pelajaran Fisika karena pembelajaran kontekstual merupakan konsep belajar yang membantu guru mengaitkan antara materi yang diajarkan dengan situasi dunia nyata dan dapat mendorong siswa membuat hubungan antara pengetahuan yang dimiliki dan penerapannya dalam situasi nyata yakni dalam kehidupan sehari-hari sehingga pemahaman konsep Fisika yang melibatkan keterlibatan siswa secara aktif baik fisik maupun mental akan mendapatkan hasil belajar siswa (Ariani, T., \& Yolanda, Y, 2019).

Menurut Fitriani, dkk (2017) Lembar kerja siswa merupakan suatu bahan ajar cetak berupa lembaran-lembaran yang di dalamnya berisi petunjuk atau langkah-langkah untuk menyelesaikan tugas-tugas yang diperintahkan di dalam lembar kerja siswa harus jelas kompetensi dasar yang akan dicapainya. Berdasarkan latar belakang yang telah dikemukakan diatas, maka peneliti tertarik untuk melakukan penelitian dengan judul "Pengembangan LKS Fisika berbasis Contextual Teaching and Learning Materi Suhu dan Kalor Pada Siswa Kelas XI SMA Negeri 6 Lubuklinggau”. Tujuan Penelitian yang ingin dicapai adalah untuk 
Mengetahui Cara Mengembangkan LKS, Mengetahui Kualitas Valid dan Praktis LKS Fisika Berbasis Contextual Teaching and Learning (CTL) Materi Suhu dan Kalor Pada Siswa Kelas XI SMA Negeri 6 Lubuklinggau

\section{LANDASAN TEORI}

Menurut Sugiyono (2010) metode penelitian dan pengembangan jika dalam bahasa Inggris adalah Research and Development adalah metode penelitian yang digunakan untuk menghasilkan sebuah produk tetentu dan menguji keefektifan produk tersebut. Menurut Tegeh, dkk (2014) mengemukakan pendapat bahwa penelitian pengembangan inovasi pembelajaran yang mampu dilakukan dengan beberapa cara yaitu: (1) Penelitian tindakan kelas, (2) Penelitian eksperimen, (3) Penelitian pengembangan pusat penelitian kebijakan dan inovasi pendidikan. Menurut Semmel (dalam Trianto, 2014:232) model 4-D adalah model yang terdiri dari 4 tahapan pngembangan yaitu : 1) Define, 2) Design, 3) Develop, dan 4) Desseminate. Tahapan yang pertama adalah Define, dalam tahapan pendifinisian ini terdapat analisis ujung depan dan analisis tugas, sedangkan untuk tahapan kedua Design dalam tahapan Design memiliki empat langkah yaitu penusunan tes acuan patokan, pemilihan media sesuai tujuan, pemilihan format. Sedangkan untuk tahapan Develop memiliki langkah validasi, stimulasi, dan uji coba terbatas, dan untuk tahapan Dessemintae adalah tahapan penyebarluasan suatu produk dalam skala yang lebih luas Menurut Rahman (2013) model adalah seperangkat prosedur yang berurutan untuk mewujudkan suatu proses, seperti penilaian kebutuhan, pemilihan media dan evaluasi dan model pembelajaran dapat dikatakan suatu desain yang menggambarkan proses rincian dan penciptaan situasi lingkungan yang dapat mengajak siswa berinteraksi, sehingga dapat merubah karakter siswa dan dapat mengembangkan ilmu pengetahuan diri siswa.

Menurut Lestari (2015) yang menyatakan bahwa model pembelajaran merupakan suatu pola interaksi antara siswa dan guru di dalam kelas yang terdiri dari strategi, pendekatan, metode, dan teknik pembelajaran yang diterapkan saat pelaksanaan kegiatan pembelajaran di kelas. Dari beberapa pendapat diatas disimpulkan bahwa model pembelajaran adalah interaksi antar siswa dan guru yang mencakup strategi pembelajaran dalam pelaksanaan kegiatan pembelajaran. Dalam hal ini bahan ajar yang akan di kembangkan yaitu lembar kerja siswa berbasis Contextual Teaching and Learning materi suhu dan kalor. Pengembangan lembar kerja siswa berbasis Contextual Teaching and Learning ini ialah serangkaian proses yang akan dilakukan untuk menghasilkan suatu produk yaitu bahan ajar 
yang berupa lembar kerja siswa yang nantinya akan digunakan sebagai sarana kegiatan pembelajaran berdasarkan teori-teori yang ada dan sudah dikembangkan. Banyak sekali model pengembangan yang telah dikembangkan oleh para ahli dalam penelitian, untuk itu dari banyaknya model yang sudah dikembangkan maka dalam penelitian pengembangan LKS fisika berbasis Contextual Teaching and Learning materi suhu dan kalor SMA Negeri 6 Lubuklinggau tahun ajaran 2020 ini. Desain model pengembangan yang digunakan adalah model 4-D (Four D) dengan 4 tahapan pengembangan, peneliti menggunakan model pengembangan 4-D (Define, Design, Develop and Desseminate) dengan tujuan bahan ajar atau lembar kerja siswa berbasis Contextual Teaching and Learning ini mampu menjadi sumber belajar yang valid dan praktis terkhusus untuk siswa di SMA Negeri 6 Lubuklinggau.

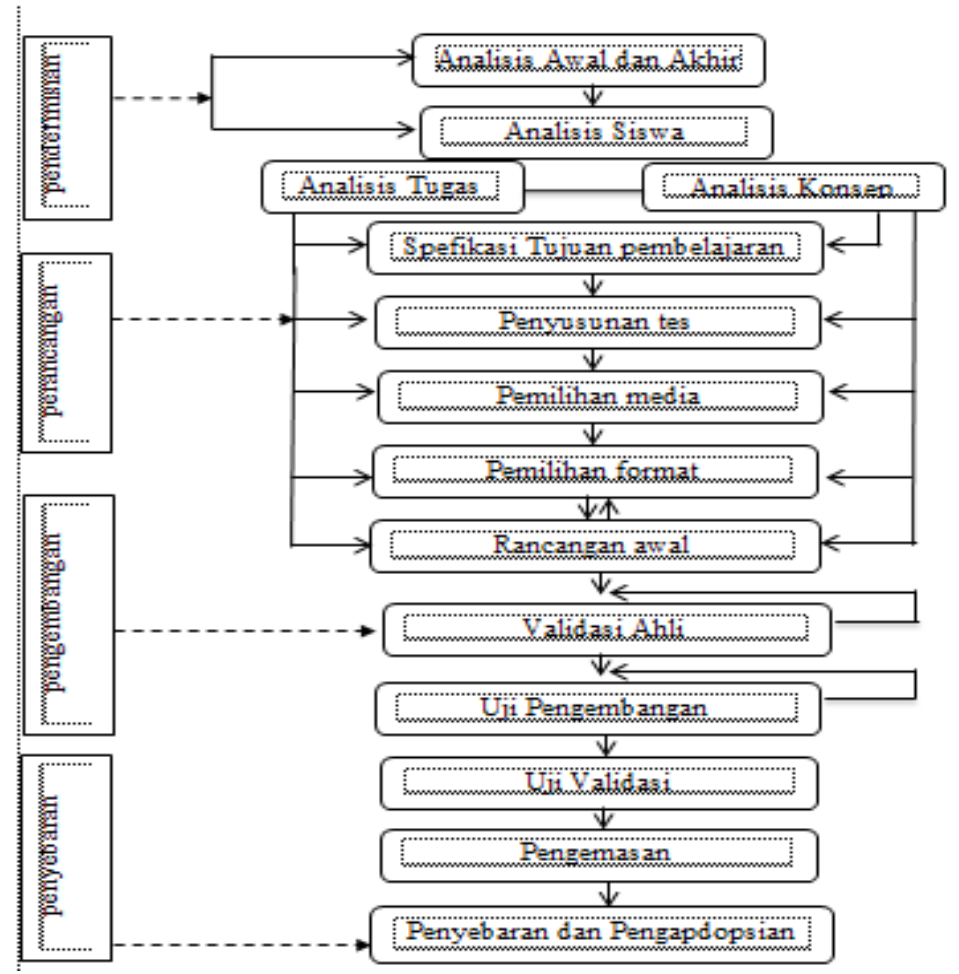

Gambar 1. Model Pengembangan 4D

Menurut Savitri (2015) yang berpendapat bahwa lembar kerja siswa adalah suatu lembaran yang dapat menjadi acuan melakukan suatu kegiatan dan dapat berfungsi untuk mencapai kompetensi yang diinginkan dalam suatu materi pembelajaran. LKS dapat membantu guru dalam mengarahkan siswa melakukan praktikum. LKS merupakan salah satu bahan ajar yang bisa digunakan sebagai sarana untuk mempermudah penyampaian materi dalam suatu pembelajaran fisika lembar kerja siswa (LKS), lembar kerja siswa adalah salah satu bahan ajar yang mempunyai peran penting dalam pembelajaran. Menurut Trianto (2011) lembar kerja siswa (LKS) merupakan bahan panduan yang digunakan siswa untuk melakukan Puplished at https://ojs.stkippgri-lubuklinggau.ac.id/index.php/SJPIF 
kegiatan penyelidikan atau pemecahan masalah. Menurut Virdaussya (dalam Herdianawati dkk, 2018) Lembar kerja siswa berupa pentunjuk, langkah-langkah untuk menyelesaikan suatu tugas yang diperintahkan dalam lembar kegiatan tersebut, sehingga peserta didik tidak sekedar memeperoleh pengetahuan yang disampaikan melainkan dapat memperoleh manfaat bagi siswa dan guru. Lembar kerja siswa adalah satu perangkat pembelajaran yang dapat memberi manfaat bagi peserta didik dan guru.

Menurut Hasibuan (2014) pembelajaran kontekstual ialah konsep belajar yang membantu guru mengaitkan antara materi yang diajarkannya dengan situasi dunia nyata siswa dan mendorong siswa membuat hubungan antara pengetahuan yang dimilikinya dengan penerapannya dalam kehidupan mereka sehari-hari, yang melibatkan tujuh komponen utama pembelajaran efektif yaitu Constructivism, Inquiry, Questioning, Learning Community, Modelling, Reflection And Authentic Assessment.. Menurut Suryani (2012) menyatakan bahwa Contextual Teaching and Learning merupakan strategi pembelajaran yang menekankan pada keterkaitan antara materi pembelajaran dengan dunia nyata. Menurut Rusman (2011) Pembelajaran kontekstual (Contextual Teaching and Learning) merupakan konsep belajar dan pembelajaran yang membantu guru mengaitkan antara materi yang diajarkan dengan situasi dunia nyata siswa, dan mendorong siswa membuat hubungan antara pengetahuan yang dimilikinya dengan penerapan dalam kehidupan nyata siswa dan keseharian mereka. Sebagai anggota keluarga, masyarakat, dan warga negara.

Tabel 1. Sintaks Pembelajaran Contextual Teaching and Learning

\begin{tabular}{|c|c|c|}
\hline Sintaks & Aktivitas Pendidik & $\begin{array}{c}\text { Aktivitas Peserta } \\
\text { didik }\end{array}$ \\
\hline Constructivisme & $\begin{array}{lr}\text { Pendidik: } & \\
\text { Memberikan } & \text { stimulasi, } \\
\text { mengarahkan } & \text { siswa } \\
\text { agar mereka } & \text { berkerja } \\
\text { sendiri } & \text { dan } \\
\text { mengkonstruksi } & \text { sendiri } \\
\text { pengetahuan } & \text { dan } \\
\text { kemampuanya } & \\
\end{array}$ & $\begin{array}{l}\text { Peserta Didik: } \\
\text { Memahami dan } \\
\text { mengkontruksi } \\
\text { sendiri pengetahuan } \\
\text { dan kemampuannya } \\
\text { pada saat proses } \\
\text { pembelajaran }\end{array}$ \\
\hline \multirow{4}{*}{ Inquiry } & Pendidik: & Peserta Didik: \\
\hline & $\begin{array}{l}\text { Mengarahkan dan } \\
\text { memotivasi siswa agar } \\
\text { mereka menemukan }\end{array}$ & $\begin{array}{lr}\text { Menemukan rendiri } \\
\text { pegetahuan dan } \\
\text { keterampilannya }\end{array}$ \\
\hline & sendiri pengetahuan dan & melalui kegiatan \\
\hline & $\begin{array}{l}\text { keterampilannya yang } \\
\text { akan dipelajari }\end{array}$ & $\begin{array}{l}\text { pengumpulan data } \\
\text { saat praktikum. }\end{array}$ \\
\hline \multirow{2}{*}{ Questioning } & Pendidik: & Peserta Didik: \\
\hline & Memberikan & Siswa menanyakan \\
\hline
\end{tabular}

Puplished at https://ojs.stkippgri-lubuklinggau.ac.id/index.php/SJPIF 


\begin{tabular}{|c|c|c|}
\hline & $\begin{array}{l}\text { kesempatan siswa untuk } \\
\text { bertanya tentang materi } \\
\text { yang belum dipahami } \\
\text { sekaligus r untuk } \\
\text { mengecek pemahaman } \\
\text { siswa }\end{array}$ & $\begin{array}{l}\text { materi dan bagian } \\
\text { pembelajaran yang } \\
\text { belum dipahami }\end{array}$ \\
\hline $\begin{array}{l}\text { Learning } \\
\text { community }\end{array}$ & $\begin{array}{l}\text { Pendidik: } \\
\text { Membuat kelompok } \\
\text { belajar sebagai wadah } \\
\text { diskusi, pertukaran } \\
\text { pendapat, Sharing. }\end{array}$ & $\begin{array}{l}\text { Peserta Didik: } \\
\text { Siswa belajar } \\
\text { berkelompok sesuai } \\
\text { dengan } \\
\text { kelompoknya }\end{array}$ \\
\hline Modeling & $\begin{array}{l}\text { Pendidik: } \\
\text { Mengarahkan } \\
\text { memberikan dan } \\
\text { serta ilustrasi } \\
\text { tentang alat yang } \\
\text { digunakan pada } \\
\text { praktikum }\end{array}$ & $\begin{array}{l}\text { Peserta Didik: } \\
\text { Mengamati arahan } \\
\text { dan mempraktekan } \\
\text { demonstrasi tentang } \\
\text { alat praktikum yang } \\
\text { digunakan pada saat } \\
\text { pembelajaran }\end{array}$ \\
\hline Refleksi & $\begin{array}{lr}\text { Pendidik: } & \\
\text { Melakukan refleksi } \\
\text { mengajak siswa untuk } \\
\text { mengulang } r \text { kembali, } \\
\text { dengan } & \text { cara } \\
\text { memberikan } & \text { soal } \\
\text { refleksi dan pertanyaan. }\end{array}$ & $\begin{array}{l}\text { Peserta Didik: } \\
\text { Merefleksi kegiatan } \\
\text { pembelajaran yang } \\
\text { baru saja dilakukan } \\
\text { dengan rara } \\
\text { mengerjakan soal } \\
\text { latihan }\end{array}$ \\
\hline $\begin{array}{c}\text { Authentic } \\
\text { assessment }\end{array}$ & $\begin{array}{l}\text { Pendidik: } \\
\text { penilaian berupa hasil } \\
\text { belajar dengan soal uji } \\
\text { kompetensi, praktikum, } \\
\text { penilaian presentasi } \\
\text { dalam ranah } \\
\text { psikomotorik, dan } \\
\text { penilian sikap afektif } \\
\text { pada tingkah laku siswa }\end{array}$ & $\begin{array}{l}\text { Peserta Didik: } \\
\text { Mengerjakan } \\
\text { dan tugas }\end{array}$ \\
\hline
\end{tabular}

Menurut Sekaran (dalam Sugiyono 2012) kerangka berpikir merupakan model konseptual tentang bagaimana teori berhubungan dengan berbagai faktor yang telah didentifikasikan sebagai masalah yang penting. Sedangkan menurut Haryoko (dalam Sugiyono, 2012) bahwa kerangka berpikir dalam suatu penelitian perlu dikemukan apabila dalam penelitian tersebut berkenaan dua variabel atau lebih. Sedangkan menurut Suriasumantri (dalam Sugiyono 2012) menyatakan kerangka teoritik merupakan sebuah penjelasan sementara terhadap gejala-gejala apa saja yang menjadi obyek dari permasalahan yang akan dijadikan sebuah penelitian. Kriteria utama agar sebuah kerangka teoritik dapat Puplished at https://ojs.stkippgri-lubuklinggau.ac.id/index.php/SJPIF 
meyakinkan sesama peneliti yaitu alur-alur berfikir yang dijelaskan secara logis guna membangun kerangka teoritik sehingga menghasilkan sebuah kesimpulan berupa hipotesis.

Berdasarkan beberapa pendapat diatas maka dapat disimpulkan bahwa kerangka teoritik merupakan sejumlah prediksi yang telah diyakini kebenarannya agar dapat mengarahkan alur pikir dalam suatu penelitian, dalam sebuah penelitian kerangka teoritik juga merupakan metode mengenai faktor-faktor yang menjadi masalah dalam penelitian dan harus dijelaskan secara logis dan sistematis setiap variabelnya.

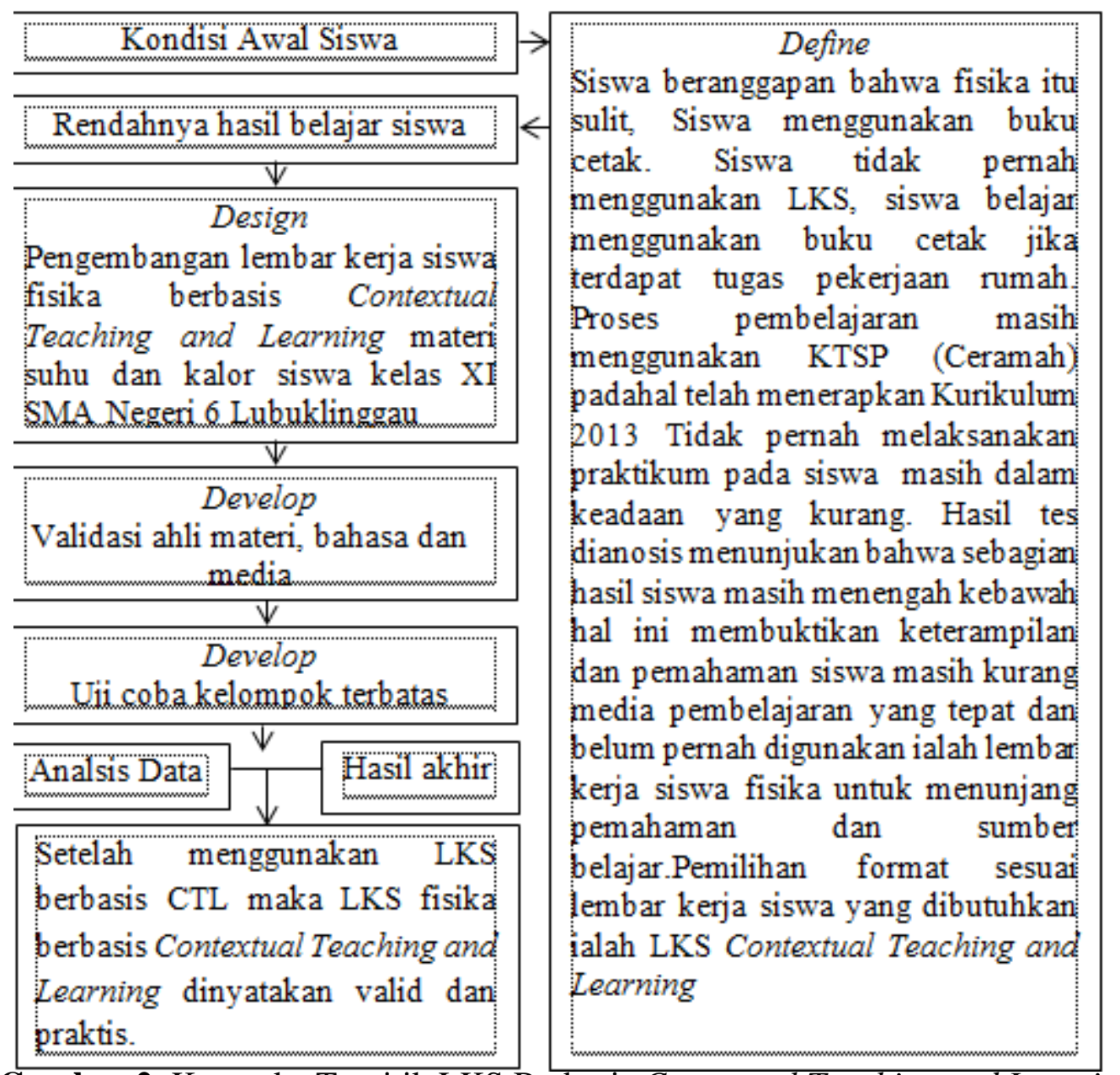

Gambar 2. Kerangka Teoritik LKS Berbasis Contextual Teaching and Learning

\section{METODE PENELITIAN/EKSPERIMEN}

Metode penelitian dalam penelitian ini menggunakan metode penelitian dan pengembangan. Model pengembangan yang digunakan adalah model pengembanagn $4 D$ merupakan model pengembangan perangkat pembelajaran model ini dikembangkan oleh semmel, Maelvyn, Dorothy, dan Thagarajan. Model 4D (Four D) berikut adalah 4 tahapan model Four $D$ yang digunakan dalam pengembangan produk lembar kerja siswa fisika. 
Model 4D (Four-D) terdiri dari 4 tahapan pengembangan yaitu Define, Design, Develop and Desseminate, akan tetapi peneliti yang menggunakan model pengembangan 4D hanya akan menggunakan sampai pada 3 tahapan saja, yaitu Define, Design dan Develop karena dalam penelitian ini tidak menyebarluaskan produk. Populasi dalam penelitian ini ialah seluruh siswa kelas XI IPA 2 SMA Negeri 6 dengan jumlah siswa sebanyak 28 siswa,sampel dalam penelitian ini adalah 6 orang siswa dengan 3 kemampuan berbeda dan teknik pengmabilan sampling menggunakan Purposive Sampling yaitu dengan pertimbangan tertentu. Dalam penelitian ini mengembangkan LKS fisika berbasis Contextual Teahing and Learning dengan menggunakan 7 sintaks dan menggunakan model pengembangan 4D (Four D) dengan 4 tahapan Define, Design, Develop dan Dessminate.

Teknik pengumpulan data dalam penelitian ini menggunakan angket, observasi, dan LKS fisika. Adapun instrumen yang digunakan yaitu analisis kualitas kelayakan dan respon siswa terhadap LKS fisika, analisis ketercapaian ketuntasan hasil belajar kognitif. Lembar kerja siswa fisika yang dikembangkan di SMA Negeri 6 Lubuklinggau sebelum diterapkan harus melewati tahap validasi oleh 3 ahli yaitu ahli materi, ahli tata bahasa, dan ahli media. Peneliti melakukan tahap penelitian yaitu dengan menggunakan uji coba kelompok terbatas. Pada uji coba kelompok terbatas peneliti menggunakan lembar angket dengan 6 orang siswa kelas X IPA 2 dan menggunakan 10 soal uji kompetensi guna menunjang kualitas kepraktisan LKS fisika yang diterapkan di kelas X IPA 2 SMA Negeri SMA Negeri 6 Lubuklinggau. Untuk menghitung skor angket validasi dan respon siswa menggunakan rumus sebagai berikut. Menurut Widoyoko (2019:236) menyatakan bahwa skor yang telah ditetapkan dapat dihitung dengan menggunakan rumusan sebagai berikut:

Skala : 4

$\mathrm{X} \quad$ : skor aktual (skor yang dicapai)

$\bar{x} \quad$ : rerata skor ideal

$:\left(\frac{1}{2}\right)$ skor (tertinggi ideal-terendah ideal)

$\mathrm{SB}_{\mathrm{i}} \quad:\left(\frac{1}{2}\right)\left(\frac{1}{3}\right)$ (skor tertinggi ideal-skor terendah ideal)

Skor tertinggi ideal : $\sum$ butir kriteria $\mathrm{x}$ skor tertinggi

Skor terendah ideal : $\sum$ butir kriteria $\mathrm{x}$ skor terendah

Menghitung rata-rata skor dengan rumus sebagai berikut

Menghitung rata-rata skor dengan rumus sebagai berikut:

(Sumber Sudjana 2017:109)

$$
\bar{x}=\frac{\sum X}{n}
$$

Keterangan :

$\bar{x} \quad=$ Skor rata-rata

Puplished at https://ojs.stkippgri-lubuklinggau.ac.id/index.php/SJPIF 
$\sum X \quad=$ jumlah skor

$n \quad=$ jumlah penilai

\section{HASIL DAN PEMBAHASAN}

\section{Hasil Penelitian}

\section{a. Validasi Materi}

Kualitas kelayakan LKS fisika berbasis Contextual Teaching and Learning pada materi suhu dan kalor ini melalui tahapan evaluasi ahli untuk melihat kevalidan LKS fisika yang divalidasi oleh ahli materi, desain serta tata bahasa sehingga LKS tersebut baik digunakan ke siswa kemudian dalam tahap kelayakan pada LKS fisika ini akan dilaksanana uji coba kelompok terbatas kelayakan LKS fisika berbasis Contextual Teaching and Learning pada kelayakan LKS fisika secara teoritik terdiri dari evaluasi ahli materi, desain serta tata bahasa secara rinci.

Tabel 2. Rentang validasi Ahli Materi Dosen Fisika

\begin{tabular}{llcc}
\hline No & \multicolumn{1}{c}{ Rentang skor (i) } & Nilai & Kategori \\
\hline 1 & $\mathrm{X}>40,8$ & $\mathrm{~A}$ & Sangat baik \\
\hline 2 & $33,6<\mathrm{X} \leq 40,8$ & $\mathrm{~B}$ & Baik \\
\hline 3 & $26,4<\mathrm{X} \leq 33,6$ & $\mathrm{C}$ & Cukup baik \\
\hline 4 & $19,2<\mathrm{X} \leq 26,4$ & $\mathrm{D}$ & Kurang baik \\
\hline 5 & $\mathrm{X} \leq 19,2$ & $\mathrm{E}$ & Sangat kurang baik \\
\hline
\end{tabular}

Berdasarkan validasi LKS fisika berbasis Contextual Teaching and Learning pada materi suhu dan kalor dosen ahli materi fisika, penilaian kevalidan LKS menurut ahli materi termasuk dalam kategori Sangat Baik dengan skor aktual sebesar 42.

Tabel 3. Rentang validasi Ahli Materi Guru Fisika

\begin{tabular}{llcl}
\hline No & Rentang skor (i) & Nilai & \multicolumn{1}{c}{ Kategori } \\
\hline 1 & $X>40,8$ & A & Sangat baik \\
\hline 2 & $33,6<X \leq 40,8$ & B & Baik \\
\hline 3 & $26,4<X \leq 33,6$ & C & Cukup baik \\
\hline 4 & $19,2<X \leq 26,4$ & D & Kurang baik \\
\hline 5 & $X \leq 19,2$ & E & Sangat kurang baik \\
\hline
\end{tabular}

Berdasarkan validasi LKS fisika berbasis Contextual Teaching and Learning pada materi suhu dan kalor dosen ahli materi fisika, penilaian kevalidan LKS menurut ahli materi termasuk dalam katagori Sangat Baik dengan skor aktual sebesar 46 


\section{b. Validasi Bahasa}

Kualitas kelayakan LKS fisika berbasis Contextual Teaching and Learning pada materi suhu dan kalor ini melalui tahapan evaluasi ahli untuk melihat kevalidan LKS fisika yang divalidasi oleh ahli bahasa yaitu dosen bahasa indonesia.

Tabel 4. Rentang Validasi Ahli Bahasa.

\begin{tabular}{llcc}
\hline No & Rentang skor $(\mathbf{i})$ & Nilai & Kategori \\
\hline 1 & $18>20,8$ & A & Sangat baik \\
\hline 2 & $16,8<\mathrm{X} \leq 20,4$ & $\mathrm{~B}$ & Baik \\
\hline 3 & $13,2<\mathrm{X} \leq 16,8$ & $\mathrm{C}$ & Cukup baik \\
\hline 4 & $9,6<\mathrm{X} \leq 13,2$ & $\mathrm{D}$ & Kurang baik \\
\hline 5 & $\mathrm{X} \leq 9,6$ & $\mathrm{E}$ & Sangat kurang baik \\
\hline
\end{tabular}

Berdasarkan validasi LKS fisika berbasis Contextual Teaching and Learning dosen ahli tata bahasa. Hasil tanggapan dari revisi pertama dengan hasil persentasinya sebesar 18 Jadi, penilaian kevalidan LKS menurut ahli bahasa termasuk dalam katagori Baik dengan skor aktual sebesar 18 .

\section{c. Validasi Media}

Kualitas kelayakan LKS fisika berbasis Contextual Teaching and Learning pada materi suhu dan kalor ini melalui tahapan evaluasi ahli untuk melihat kevalidan LKS fisika yang divalidasi oleh ahli media yaitu dosen fisika.

Tabel 5. Rentang Validasi Ahli Media

\begin{tabular}{llcc}
\hline No & Rentang skor (i) & Nilai & Kategori \\
\hline 1 & $34>30,6$ & A & Sangat baik \\
\hline 2 & $25,2<\mathrm{X} \leq 30,6$ & B & Baik \\
\hline 3 & $19,8<X \leq 25,2$ & C & Cukup baik \\
\hline 4 & $14,4<X \leq 19,8$ & D & Kurang baik \\
\hline 5 & $\mathrm{X} \leq 14,4$ & E & Sangat kurang baik \\
\hline
\end{tabular}

Berdasarkan validasi LKS fisika berbasis pada materi suhu dan kalor dosen ahli media. Hasil tanggapan ahli media dengan hasil 34. Jadi, penilaian kevalidan LKS menurut ahli media termasuk dalam katagori Sangat Baik dengan skor aktual sebesar 34. Berdasarkan penilaian dari ketiga orang ahli validasi terhadap LKS fisika berbasis Contextual Teaching and Learning pada materi suhu dan kalor yang sudah diuraikan di atas menunjukkan penilaian yang baik. Oleh karena itu, LKS fisika berbasis Contextual Teaching and Learning dapat dikatakan valid dan dapat digunakan untuk tahap uji coba yang akan dilaksanakan di SMA Negeri 6 Lubuklinggau. Berikut hasil perhitungan rekapitulasi hasil dari tiga ahli dapat dilihat di tabel. 
Tabel 6. Rekapitulasi Validasi Ahli

\begin{tabular}{cccc}
\hline No & Validasi & Skor & Kategori \\
\hline 1 & Validasi Materi 1 & 42 & Sangat Valid \\
\hline 2 & Validasi Materi 2 & 46 & Sangat Valid \\
\hline 3 & Validasi Bahasa & 18 & Valid \\
\hline 4 & Validasi Media & 34 & Sangat Valid \\
\hline & Total & 140 & - \\
\hline & Rata-Rata & 35 & Sangat Valid \\
\hline
\end{tabular}

\section{d. Uji Kelompok Terbatas}

Dalam LKS fisika berbasis Contextual Teaching and Learning pada materi suhu dan kalor pada kelayakan LKS fisika terdiri dari pelaksanaan uji kelompok terbatas kelayakan LKS fisika berbasis Contextual Teaching and Learning di sekolah SMA Negeri 6 Lubuklinggau tahun pelajaran 2020/2021 pada semester gajil di kelas XI IPA 2 yang mendapatkan hasil sebagai berikut.

Tabel 7. Skor Angket Respon Siiswa Uji Kelompok Terbatas

\begin{tabular}{cccc}
\hline No & Kode Siswa & Skor & Kategori \\
\hline 1 & S-1 & 36 & Sangat Setuju \\
\hline 2 & S-2 & 30 & Setuju \\
\hline 3 & S-3 & 34 & Sangat Setuju \\
\hline 4 & S-4 & 38 & Sangat Setuju \\
\hline 5 & S-5 & 38 & Sangat Setuju \\
\hline 6 & S-6 & 39 & Sangat Setuju \\
\hline
\end{tabular}

Untuk menunjang kepraktisan LKS berbasis Contextual Teaching and Learning materi suhu dan kalor peneliti juga melaksanakan pemberian angket respon guru terhadap LKS fisika tersebut.Berikut adalah hasil angket respon guru

Tabel 8. Skor Angket Respon Guru Uji Kelompok Terbatas

\begin{tabular}{cccc}
\hline No & Kode Guru & Skor & Kategori \\
\hline 1 & G-1 & 39 & Sangat Setuju \\
\hline
\end{tabular}

Berikut adalah tabel rekapitulasi nilai keseluruhan agket respon guru dan siswa pada uji kelompok terbatas.

Tabel 9. Rekapitulasi Skor Angket Respon Uji Kelompok Terbatas

\begin{tabular}{cccc}
\hline No & Kode Siswa & Skor & Kategori \\
\hline 1 & S-1 & 36 & Sangat Setuju \\
\hline 2 & S-2 & 30 & Setuju \\
\hline 3 & S-3 & 34 & Sangat Setuju \\
\hline 4 & S-4 & 38 & Sangat Setuju \\
\hline 5 & S-5 & 38 & Sangat Setuju \\
\hline 6 & S-6 & 39 & Sangat Setuju \\
\hline 7 & G-1 & 39 & Sangat Setuju \\
\hline & Total & 254 & -
\end{tabular}




\section{e. Soal Uji Kompetensi Kelompok Terbatas}

Dalam pelaksanaan tugas uji kompetensi dilakukan untuk melihat kepraktisan dari LKS fisika tersebut, guna menunjang kepraktisan dari LKS yang dikembangkan peneliti melihat ketuntasan nilai hasil uji kompetensi siswa di kelas XI IPA 2. Tugas ini dilaksanakan pada saat setelah pemberian angket kepraktisan dengan menggunakan waktu 2 jam pelajaran dengan cara menggunakan Whasapp Group. Dalam hal ini soal yang diberikan berupa soal ganda dengan katagori C2-C3 yang berjumlah 10 soal. Soal yang digunakan telah valid dan reliabel karena soal yang digunakan bersal dari soal UN dan USBN.

Berdasarkan perhitungan ketuntasan hasil belajar siswa segi kognitif bisa dikatakan praktis jika siswa mendapatkan nilai $>73$ Uji kompetensi yang dilaksanakan mendapatkan hasil bahwa dari 6 siswa yang menjadi sampel 2 diantaranya mendapat nilai $<73$ sehingga bisa dikatakan tidak tuntas karena nilai yang diperoleh di bawah Kriteria Ketuntasan Minimal $(\mathrm{KKM})$, sedangkan untuk 4 orang siswa lainya mendapat nilai $>73$ sehingga hasil uji kompentensi 4 orang siswa tersebut dikatan tuntas. Berdasarkan informasi diatas persentase ketuntasan siswa lebih dari 73, maka dari itu jumlah keseluruhan siswa dengan hasil yang dihitung mencapai 76,5\% sehingga LKS Fisika Berbasis Contextual Teaching and Learning materi suhu dan kalor dikatakan praktis dan LKS tersebut layak untuk diterapkan dan digunakan. Berikut adalah hasil uji kompetensi uji kelompok terbatas.

Tabel 10. Rekapitulasi Skor Angket Respon Uji Kelompok Terbatas

\begin{tabular}{ccccc}
\hline No & Kode Siswa & Skor & KKM & Kategori \\
\hline 1 & S-1 & 90 & 73 & Tuntas \\
\hline 2 & S-2 & 81 & 73 & Tuntas \\
\hline 3 & S-3 & 81 & 73 & Tuntas \\
\hline 4 & S-4 & 81 & 73 & Tuntas \\
\hline 5 & S-5 & 66 & 73 & $\begin{array}{c}\text { Tidak } \\
\text { Tuntas }\end{array}$ \\
\hline 6 & S-6 & 60 & 73 & $\begin{array}{c}\text { Tidak } \\
\text { Tuntas }\end{array}$ \\
\hline & & & & - \\
\hline & Total & 475 & - & Tuntas \\
\hline
\end{tabular}

\section{KESIMPULAN}

Berdasarkan penelitian, peneliti menyimpulkan bahwa Peneliti mengembangkan LKS fisika berbasis Contextual Teaching and Learning. Pengembangan LKS fisika berbasis Contextual Teaching and Learning yang dilakukan dengan model pengembangan Four D 
(4D) melalui 4 tahap tahapan mulai dari define, design, develop dan disseminate namun untuk tahapan disseminate tidak dilaksanakan karena peneliti memiliki keterbatasan materi, biaya dan adanya wabah Covid-19. Penilaian kelayakan terhadap kualitas LKS fisika berbasis Contextual Teaching and Learning secara keseluruhan adalah 35 LKS fisika berbasis Contextual Teaching and Learning dikatakan valid dan memenuhi kriteria sangat baik. Persentase keseluruhan respon siswa terhadap LKS fisika berbasis Contextual Teaching and Learning adalah 36,2 sehingga LKS dikatakan praktis dan memenuhi kriteria sangat setuju atau positif.

Hasil nilai uji kompensi yang dibandingkan dengan Kriteria Ketuntasan Mininal (KKM) dari 6 orang siswa yang mendapat nilai $>73$ adalah 4 orang, sedangkan sisanya 2 orang siswa mendapat nilai $<73$ sehingga dapat dilihat bahwa rerata ketuntasan siswa adalah $80 \%$ sehingga LKS fisika berbasis Contextual Teaching and Learning Materi Suhu dan Kalor pada Siswa Kelas XI SMA Negeri 6 Lubuklinggau dinyatakan valid dan praktis. Adapun saran pemanfaatan dan pengembangan produk lebih lanjut adalah sebagai berikut: Peneliti menyarankan LKS fisika berbasis Contextual Teaching and Learning dapat digunakan dalam pembelajaran setelah pandemik Covid-19 materi suhu dan kalor karena telah mendapatkan nilai penilaian sangat baik dan layak digunakan. LKS fisika berbasis Contextual Teaching and Learning bisa dikolaborasikan dengan model pembelajaran yang lain selama menyertakan tujuh komponen penting dalam pembelajaran Contextual Teaching and Learning

\section{DAFTAR PUSTAKA}

Ariani, T., \& Yolanda, Y. (2019). Effectiveness of Physics Teaching Material Based on Contextual Static Fluid Material. Kasuari: Physics Education Journal (KPEJ), 2(2), 70-81.

Atma, A. (2019). Pengembangan kurikulum berbasis pendidikan berkarakter.Jurnal Pendidikan dasar. 1 (1), 31-43

Fitriani W, dkk. (2017).Pengembangan lembar kerja siswa (LKS) fisika untuk melatih kemampuan berfikir tingkat tinggi (High Order Thingking Skill) siswa SMA. Jurnal Wahana pendidikan fisika. 2 (1), 36-42

Hasibuan, I. (2014) Model pembelajaran Contextual Teaching and Learning. Jurnal Logaritma 2 (1), 1-12

Lestari, E. \& Yudhanegara, R. (2015). Penelitian pendidikan matematika. Bandung : Refika Aditama

Rahman, M. \& Amri, S. (2013). Strategi Dan Desain Pengembangan Sistem Pembelajaran. Jakarta: Prestasi Pustakaraya. 
Salahudin, Anas. (2011). Filsafat Pendidikan. Bandung: Pustaka Setia

Rusman. (2011). Model-Model Pembelajaran: Mengembangkan Profesionalisme Guru. Jakarta: Rajawali Pers.

Sugiyono. (2007). Metode Penelitian Pendidikan Pendekatan Kuantitatif, Kualitatif, dan $R \& D$. Bandung: Alfabeta.

Sugiyono. (2010). Metode Penelitian Pendidikan Pendekatan Kuantitatif, Kualitatif, dan $R \& D$. Bandung: Alfabeta.

Sugiyono. (2012). Metode Penelitian Pendidikan Pendekatan Kuantitatif, Kualitatif, dan $R \& D$. Bandung: Alfabeta.

Syamsu, D. F. (2017). Pengembangan LKS Biologi berbasis kontekstual dilengkapi dengan Mind Map pada materi Archaebacteria dan Eubacteria untuk siswa SMA. Jurnal Bionatural. 4 (1), 26-34

Tegeh, I.M., dkk. (2014). Model Penelitian Pengembangan. Yogyakarta: Graha Ilmu.

Widyoko (2019). Evaluasi Program Pembelajaran. Yogyakarta: Pustaka Pelajar

Syahli, R. O., Ariani, T., Si, M. P., \& Charli, L. (2017). Pengembangan Bahan Ajar Fisika Berbasis Kontekstual Materi Impuls dan Momentum Pada Siswa Kelas X di SMA Negeri 1 Lubuklinggau Tahun Pelajaran 2016/2017. Skripsi tidak dipublikasikan. Lubuklinggau: STKIP-PGRI Lubuklinggau. 